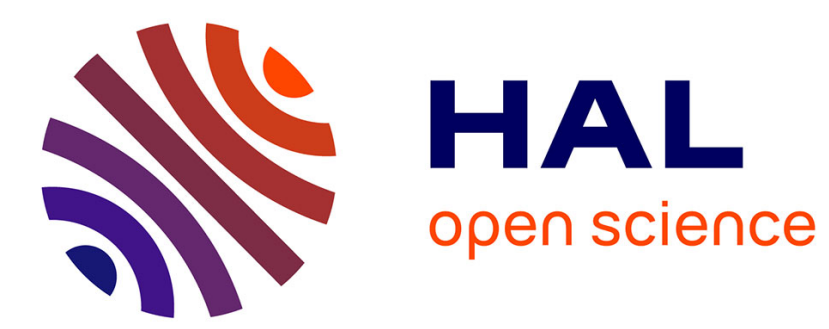

\title{
EXAFS study of zirconia precursors
}

\author{
C. Landron, J. Rifflet, P. Odier, Dominique Bazin
}

\section{To cite this version:}

C. Landron, J. Rifflet, P. Odier, Dominique Bazin. EXAFS study of zirconia precursors. Journal de Physique IV Proceedings, 1993, 03 (C7), pp.C7-1413-C7-1416. 10.1051/jp4:19937217 . jpa-00251852

\section{HAL Id: jpa-00251852 https://hal.science/jpa-00251852}

Submitted on 1 Jan 1993

HAL is a multi-disciplinary open access archive for the deposit and dissemination of scientific research documents, whether they are published or not. The documents may come from teaching and research institutions in France or abroad, or from public or private research centers.
L'archive ouverte pluridisciplinaire HAL, est destinée au dépôt et à la diffusion de documents scientifiques de niveau recherche, publiés ou non, émanant des établissements d'enseignement et de recherche français ou étrangers, des laboratoires publics ou privés. 


\title{
EXAFS study of zirconia precursors
}

\author{
C. LANDRON, J.C. RIFFLET, P. ODIER and D. BAZIN* \\ Centre de Recherches sur la Physique des Hautes Températures, 45071 Orléans cedex 2, France \\ * Laboratoire pour l'Utilisation du Rayonnement Electromagnétique, 91405 Orsay cedex, France
}

\begin{abstract}
An original process has been developed for the synthesis and the characterization of spherical zirconia powders having high densifying ability. This technique is based on the nebulization of a zirconium precursor solution followed by a suitable heat treatment. Structural characterization of the starting precursor has been achieved by an in situ EXAFS analysis of the nebulised precursor in the form of an aerosol. We have shown that high purity, chemical homogeneity, particle size and sphericity which are requested for improving the ceramic elaboration, are related to the structural characteristics during the synthesis. Improvement of the mechanical properties of the ceramic relie on a bette knowledge of the pre-sintering steps involving structural transformations of the precursor.
\end{abstract}

\section{INTRODUCTION}

Ceramics have numerous applications in a wide spectrum of human activities. Routes to their elaboration commonly use powders which are processed to form further suitable materials for practical use such as high temperature mechanical applications. Among elaboration techniques, the spray pyrolysis method presents many advantages [1] for producing efficient powders for compacting and sintering. We have developed an experimental device [2,3], see Figure 1, in order to prepare and characterize zirconia powders. The choice of zirconia is justified by the possibilities of its application in the field of ceramics with improved mechanical properties. The powders are formed by the nebulization of aqueous solutions of zirconium salts followed by an appropriate thermal treatment. We have used piezoelectric transducers designed by RBI (Meylan-France). The elaboration process is accounted for the quality of the powders composed with particles which can be described as nearly spherical, microsized, monodisperse and homogeneous, they are then highly suitable for sintering.

EXAFS has been used as a local probe to give structural informations concerning aerosols formed by liquid or amorphous compounds [4]. This technique was applied to characterize the evolution of the zirconium environment between its precursor liquid state and its final crystallized $\mathrm{ZrO}_{2}$ form. Our final motivations are to evaluate the influence of anion complexing power which is an important problem in powder elaboration from liquid precursors and possibly to study the correlations between the complexing anion power and the final particle morphology. 
In situ EXAFS analysis was performed near the zirconium $\mathrm{K}$-edge on nebulized samples formed from aqueous solutions of zirconium and yttrium chloride and compared to these formed from nitrates of these elements. The results show that this technique is very useful for on line studies of the evolution of the local structure of the precursors during ceramic elaboration process.

\section{EXPERIMENTAL}

The Radial Distribution Function around $\mathrm{Zr}$ atoms is determined by EXAFS : on the one hand for in situ experiments concerning nebulized solutions containing zirconia precursors and on the other hand for post mortem experiments concerning dried samples elaborated by nebulization at different temperatures. The experimental device for in situ determination is shown on Figure 1. The aerosol is circulated in the analysis chamber where it is irradiated by the X-ray beam. The measurements of the zirconium absorption threshold have been performed at LURE (Orsay). The synchrotron radiation was provided by the $1.85 \mathrm{GeV}$ storage ring of DCI. The positron intensity was $300 \mathrm{~mA}$ at the beginning of the run with a life time of 95 hours. The white X-ray beam was monochromatized by a double Bragg reflection $\mathrm{Si}(311)$. The absorption was measured, at room temperature, on the $\mathrm{Zr}$ K-edge (17900-19000 eV energy range) with a fluorescence detection mode on the XAS IV station.

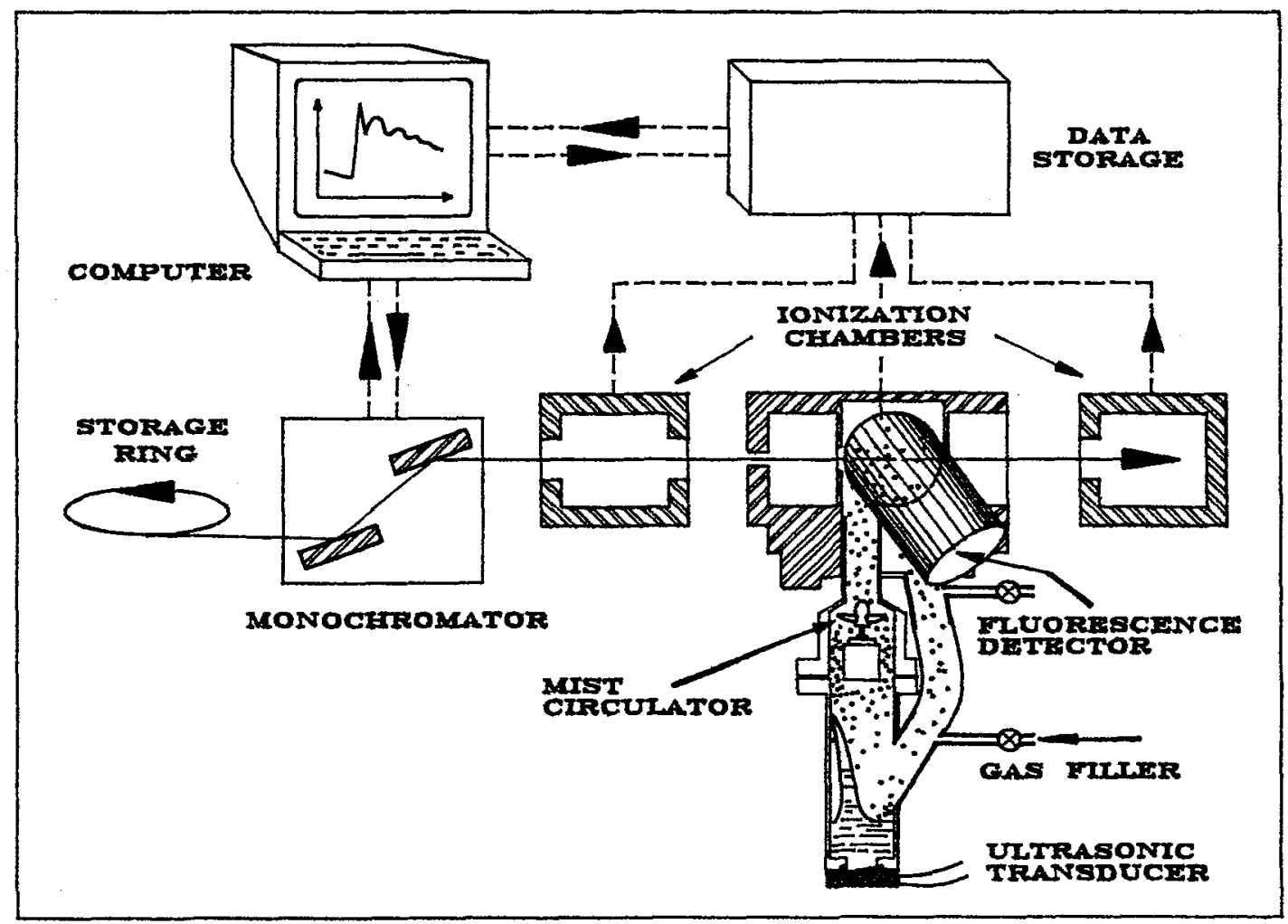

Fig. 1 : Schematic diagram of the experimental device used for EXAFS analysis with a fluorescence detection mode. Aerosol circulates in the analysis chamber where it is irradiated by the $X$-ray beam. 


\section{EXAFS MEASUREMENTS}

The treatment of EXAFS spectra gives structural informations associated with the Radial Distribution Function that can be directly obtained from Fourier transform of measured data. The EXAFS spectrum for $\mathrm{Zr}$ in zirconia is treated by considering a nearest neighbor shell of oxygen atoms around $\mathrm{Zr}$. Experimental data were exploited by using the recommended procedure of the International Workshop on Standards and Criteria in XAFS [5]. The EXAFS spectra were also transformed on the basis of the theory of X-ray absorption developed by Teo [6]: the EXAFS oscillations in $\mathrm{k}$ space are obtained from the experimental data by a background subtraction obtained after a threshold normalization. The Fourier transform of the oscillations yields a partial radial distribution function which is uncorrected for amplitude and phase shift describing the $\mathrm{Zr}$ surrounding. The Figure 2 reports a plot of the module and imaginary part of the Fourier transformed $\mathrm{k}^{3}$-weighted EXAFS experimental spectrum (a Hanning window was used for apodization). A convenient inverse Fourier transform isolates the first zirconium oxygen coordination shell with the corresponding values of atomic distances and coordination numbers. A multi-parameter least squares fitting procedure has been used for determining the oxygen coordination shell, this procedure needs theoretical values of phases and amplitudes of waves functions taken from McKale et al. [7]. The coordination numbers, interatomic distances, energy thresholds and Debye-Waller factors are taken as adjustable parameters in the fitting program.

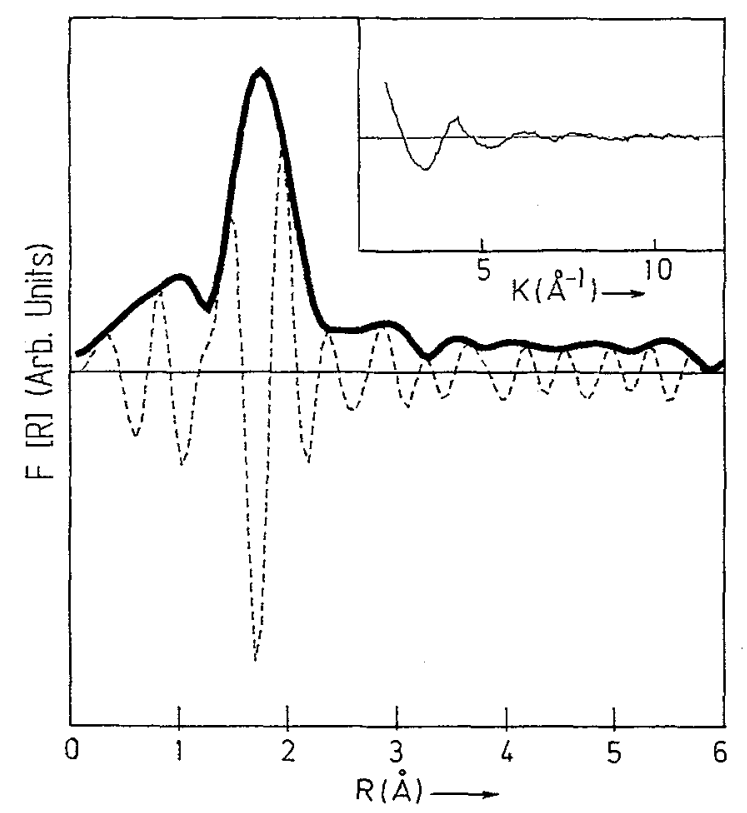

Fig. 2: Pseudo-radial distribution function ( $2 r K$ edge) of a nebulized zirconium nitrate aqueous solution (0.5 normal). The plot represents the module (full line) and the imaginary part (dotted line) of the Fourier transform $T F(R)$ of the $k^{3} \chi(k)$ function. Phase shift is not taken into account. The $X(k)$ oscillations are shown in the inset. 


\section{RESULTS}

Crystallised zirconyle nitrate has been examined and compared to nebulized zirconium nitrate solution (at room temperature). Both cases are very similar indicating that the zyrconyle nitrate has in fact a local structure similar to that of the hydrated form $\mathrm{Zr}(\mathrm{OH})_{2}\left(\mathrm{NO}_{3}\right)_{2} 4.7 \mathrm{H}_{2} \mathrm{O}$ resolved by bénard et al [8], moreover their local structure is preserved in solution. In this case, zirconium atoms are surrounded by eight oxygen atoms : four located at $0.211 \mathrm{~nm}$ and the others at $0.230 \mathrm{~nm}$. These values agree with the mean value determined previously by X-ray diffraction technics [9]. These datas were compared with those obtained from dried powders by heat treating the nebulised particles of zirconium nitrate solutions (at a dilution rate corresponding to 0.1 mole/1) [2]. Only one oxygen shell were detected at that time, possibly due to an averaging in high dilution. No significant modifications of the zirconium environment was observed during the first stage of drying up to $100^{\circ} \mathrm{C}$ : in this range $\mathrm{d}(\mathrm{Zr}-\mathrm{O})=0.223 \mathrm{~nm}$ and $\mathrm{N}(\mathrm{O})=7.7$. Above this temperature, a modification of the second shell $(\mathrm{Zr}-\mathrm{Zr})$ is noticed traducing an increasing number of zirconium atoms. This fact is probably related with the formation of linked chains $\left[\mathrm{Zr}(\mathrm{OH})_{2}\left(\mathrm{NO}_{3}\right)\left(\mathrm{H}_{2} \mathrm{O}\right)_{2}{ }^{+} \mathrm{ln}\right.$. The distance $\mathrm{d}(\mathrm{Zr}-\mathrm{Zr})=0.343 \mathrm{~nm}$ is in fact in between that of crystallised tetragonal zirconia $(0.364 \mathrm{~nm})$ and amorphous zirconium oxide $(0.33 \mathrm{~nm})$ possibly due to the presence of some earlier crystallised fraction of the probed sample. Indeed its crystallisation at a macroscopic scale occurs above $400^{\circ} \mathrm{C}, \mathrm{d}(\mathrm{Zr}-\mathrm{Zr})$ then reaches $0.365 \mathrm{~nm}$. Similar work has been recently undertaken on zirconium sulfate which is much more engaged in the zirconium coordination sphere than the nitrate or even than the chloride group due to a higher complexing power. This is only in the range of $800^{\circ} \mathrm{C}$ (at least above $650^{\circ} \mathrm{C}$ ) that characteristics values of the crystallized structure comes out indicating a retarded macroscopic crystallisation for the sulfate precursor with respect to that of the nitrate. This may have important consequences on the final microstructure of the powders.

\section{CONCLUSION}

Our results enable to describe the part of anions of chemical precursors to ceramic powders by determining the modifications of the environment of zirconium atoms in $\mathrm{ZrO}_{2}$ samples during synthesis by the atomization process. We have evaluated the correlation between the particle morphology and the complexing anion power. In order to investigate the influence of anion complexing power, EXAFS has been used as a local probe for determining the Radial Distribution Function around $\mathrm{Zr}$ atoms in samples elaborated at different temperatures.

\section{REFERENCES}

[1] S. Arnold, "Spectroscopy of single levitated micron sized particles", in Optical effects Associated with Small Particles, Ed. S. Ramaseshan, Word Publishing Co., Singapore, (1988) p.203.

[2] C. Landron, Ph. Odier and D. Bazin, J. Aerosol Sc., 23, (1992) 413.

[3] C. Landron, Ph. Odier and D. Bazin, Europhysics Let., 21, (1993) 859.

[4] D. C. Koningsberger, X-Ray Absorption, Willey Interscience Publ., New-York, (1988) p. 373.

[5] International Workshops on Standards and Criteria in XAFS, Physica B, 158, (1989) 701.

[6] B. K. Teo, "EXAFS : basic principles and data analysis", Inorg. Chem. Conc., Vol. 9, Springer Verlag, Berlin, (1986) p. 26.

[7] A. G. McKale, B. W. Veal, A. P. Paulikas, S. K. Chan, G. S. Knapp, J. Amer. Ceram. Soc., 110, (1988) 3763.

[8] P. Bénard, M. Loüer and D. Loüer, J.Solid State Chem., 94, (1991) 27.

[9] D.B. mc Whan and G. Lundgren, Acta Cryst., 16, (1963), A 36. 